\title{
Die Haftung für culpa in contrahendo in Polen und in Deutschland
}

\author{
Eine Analyse im Kontext des europäischen und internationalen Privatrechts
}

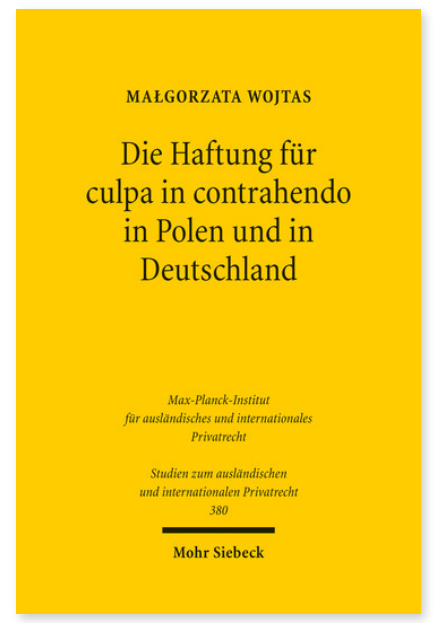

2017. XXIV, 320 Seiten. StudIPR 380

ISBN 978-3-16-155373-8

DOI 10.1628/978-3-16-155373-8

eBook PDF 69,00€

ISBN 978-3-16-155174-1

fadengeheftete Broschur 69,00€
Die Haftung für culpa in contrahendo beschreibt die Verantwortlichkeit der Verhandlungsparteien für ihr Fehlverhalten in der vorvertraglichen Phase. Was stellt ein vorvertragliches Fehlverhalten dar und welche haftungsrechtliche Konsequenzen löst es aus? Trotz fortschreitender Harmonisierung des europäischen Vertragsrechts ist dies bis heute im polnischen und deutschen Rechtssystem unterschiedlich geregelt. Małgorzata Wojtas arbeitet zunächst eine europarechtliche Definition der culpa in contrahendo heraus, welche anschließend als Grundlage für einen Rechtsvergleich der deutschen und polnischen Gestaltung der vorvertraglichen Haftung verwendet wird. Danach arbeitet sie einheitliche Grundsätze der vorvertraglichen Haftung im polnischen Recht heraus. Abschließend untersucht sie verschiedene Lösungen der rechtlichen Gestaltung von grenzüberschreitenden Rechtsgeschäften auf Grundlage des europäischen und internationalen Privatrechts, mit welchen sich die aus den festgestellten national-rechtlichen Differenzen resultierenden Nachteile vermeiden lassen.

Małgorzata Wojtas Geboren 1987; Studium der Rechtswissenschaften in Posen (Polen), Metz (Frankreich) und Frankfurt/Oder; Bachelor und Master of German and Polish Law an der Europa Universität Viadrina in Frankfurt/Oder; 2016 Promotion an der Universität Regensburg; Stipendiatin der Konrad-Adenauer-Stiftung; Referendarin am OLG Brandenburg und wissenschaftliche Mitarbeiterin in einer großen deutschen Wirtschaftskanzlei.
Jetzt bestellen:

https://mohrsiebeck.com/buch/die-haftung-fuer-culpa-in-contrahendo-in-polen-und-in-deutschland-9783161553738? no_cache=1

order@mohrsiebeck.com

Telefon: +49 (0)7071-923-17

Telefax: +49 (0)7071-51104 